Ann Natl Acad Med Sci (India), 54(4): i-iii, 2018

\title{
Editorial
}

\section{Ensuring Healthy Community: Tapping them Young}

It is a saying that "Health is Wealth" and no matter how much wealth one has, it loses its significance if one is not healthy enough to enjoy it. There are wide individual variations regarding health-seeking behaviors. With the launch of National Health Mission, it has been observed that the availability of facilities nearby has encouraged residents especially to avail those facilities which will result in minimization of transportation cost. Literacy and health status has a strong correlation with facilities effective utilization but varies on a regional scale with Kerala still at the top (1). While studying various health-seeking behaviors among pregnant women, Das and Sarkar found that doctors and para-medical staff were only consulted during complications. Lack of access to health care and pregnancy-related health information led their study participants to rely heavily on information and misconceptions about pregnancy gathered from elder women, friends, and mothers-in-law and husbands (2).

Children usually spend on an average 6-8 hours of a day in a school. Schools have a great responsibility in shaping their habits and healthy behavior apart from scholastics development. School educators are now concerned more than ever on observing marked lifestyle changes among children especially teenagers. Personal communication from a teacher revealed decreased activity among children to the extent that they demand to pick up vehicle to be at their doorsteps. Smartphone overuse is another concern resulting in poor concentration and sleepiness in classes. The good thing coming from schools is optimism and openness to change these attitudes through innovations towards positive behaviors. Policy changes like Right to Education (RTE) in 2009 have enhanced literacy levels for marginalized children, but they still lag behind educational goals. Both recognized (Government and Private) and unrecognized Alternative schools (owned by people showing passion for teaching) are willing to comply with the RTE Act. Unrecognized schools face challenges of closure and quality of education (3). The disadvantaged population prefers these schools because of proximity to their home or workplace and much lower fees than that charged by private schools. However, continuity of education for higher grades is harder since these schools are unable to provide Migration Certificates. Various NGOs and independent researchers have raised the plight of these schools at the various platform.

Adolescent health education issues have been discussed widely in the medical literature (4). The most important indicator of the health of a country is the Infant Mortality Rate (IMR). India has achieved a marked decline in IMR in the last few decades, but reduction below 30 is still a distant dream. The significant portion of IMR is due to Neonatal and Perinatal deaths. Improved neonatal and obstetric services have decelerated neonatal deaths, but a further reduction is highly dependent on maternal health and socio-cultural factors. There are still gaps in nutritional problems among pregnant women and adolescent girls despite various health programs. The health of both women and men is essential for reproductive health. Health care is sought only once a woman is pregnant. However, once pregnant it becomes too late for health interventions that should be initiated much before. Adolescent health education is one such initiative to improve the overall health of the community. Though results will not be immediately available but considering the synergistic effect with improving secular trends of education, such interventions are expected to have very high long term impact. Research from the West about reproductive health have shown favorable time trend results compared to a study in 2001 (5).

It has also been shown that children are more receptive to ideas and they can be molded readily into a persona society needs. For example, Tragler had shown that giving information about nutrition, 
hygiene, immunization to children between 12-16 years not only leads to increased awareness but casts away misconceptions (6). Children can also be a carrier for changes in transmitting the current health information to their parents (7). Joyful methods are the most cost-effective in bringing about desired knowledge and behavior changes (8).

Howsoever easy it may sound but is not without challenges. An American study found that integrating health education efforts within core curricula classes can lead to favorable outcomes. However, it also cautioned that implementation barriers must be actively addressed by schools and program developers to improve program fidelity and maximize the sustainability of program gains (9). The challenge becomes enormous in the present era where parental- student focus moves towards demanding competitive examinations heavily reliant on cognitive skills as a student moves to $9^{\text {th }}$ grade. In such a situation it will be determined mainly by the ingenuity of the teachers to incorporate such programs in their routine school schedule.

The role of physicians, curriculum planners, developmental pediatrician, educationists to come together to plan and implement an innovativehealth program,without compromising the school schedule, is need of the hour. This is the most crucial step. Many times teachers do have creative ideas to experiment with the students. However, rigidness of the schedule, regulatory issues and fear of controversy with some sensitive information often hold them back. The developmental pediatrician and educationists will be the best guide for preparing developmentally appropriate educational program coupled with scientifically provenauthentic information from physicians. Teachers' role enhances manifold as they teach, acknowledge, demonstrate, model, provide feedback, encourage, provide assistance, ask questions and give directions to the students.

Though there are many theories behind the human brain and psychological development but most acceptable is that of Erikson's psycho-development theory which spans the whole life of an individual. Out of eight stages of development, stage 4 and five need to be considered while preparing educational activities and modules. Stage 4 focus on industry vs. inferiority where children between ages 5-11 need to cope with new social and academic demands. Success leads to a sense of competence. For a health education program to be effective child should be given the material in chunks and adequate time to be provided for every child to assimilate the information. Stage 5 focus on children between ages 12- 18 years where Teens need to develop a sense of self and personal identity. This adolescent stage is the period of turmoil and is also referred to as a hormonal stage. Significant changes in lifestyle can be implemented at this stage.

Martin and other using standard Cochrane procedure analyzed 18 randomized clinical trials (RCTs) and have shown that school and community-based physical activity interventions as part of obesity prevention or treatment programme can benefit executive functions of children with obesity or overweight specifically (10).

In India, school health promotion has been practiced for many years in the form of health check-ups, school health services, health education and as a life skills initiative. However, only recently it has been recognized to have immense potentials. The many States in India, mostly from the South, have implemented health programs in different forms. The National Health Policy 2017 while relying heavily on Universal Health Coverage emphasized investment and action in school health- by incorporating health education as part of the curriculum, promoting hygiene and safe health practices within the school environs and by acting as a site of primary health care. Taking a cue from the policy, Ministry of Health and Family Welfare (MoHFW) and Ministry of Human Resource Development (MHRD) joined hand under the Honorable Prime Minister Shri Narendra Modi's Ayushman Bharat initiative launched on April 14, 2018, at Bijapur, Chattishgarh to promote School Health Education. 
They were entrusted with designing a school health program targeting school children and adolescents. The program will integrate various existing initiatives including those by Rashtriya Kishore SwasthyaKaryakram (RKSK) in the Indian context to promote the holistic development of children and a healthy community.

National Academy of Medical Sciences (India) is committed to promoting public health, develop skilled human resources and validate various medical, scientific initiatives with its precious resources of expertise of its distinguished Fellows and young, energetic members. The Academy also felicitate the biomedical scientists in the country through awards, honors, orations at its annual conferences and through the dissemination of high-quality scientific knowledge and skills through Continuing Medical Education, Symposia and Workshops. The Academy supports activities which may assist a wide range of health care professionals to acquire contemporary skills and knowledge to provide the best practice evidence-based healthcare to ensure a healthy community. We wish readers A Happy New Year.

Kuldeep Singh

Sanjeev Misra

References

1. Jana A, Basu R (2017). Examining the changing health care seeking behavior in the era of health sector reforms in India: evidences from the National Sample Surveys 2004 \& 2014. Glob Health Res Policy 2:6.

2. Das A, Sarkar M (2014). Pregnancy-related health information-seeking behaviors among rural pregnant women in India: validating the Wilson model in the Indian context. Yale J Biol Med 87(3):251-262.

3. Sharma K, Ibrar M (2018). Why unrecognised Delhi schools are still trusted. Time of India Feb 10. Accessed at https://timesofindia.indiatimes.com/ home/ education/ news/ whyunrecognised-schools-are-still-trusted/articleshow/ 62857015.cms.

4. Sivagurunathan C, Umadevi R, Rama R, Gopalakrishnan S (2015). Adolescent health:present status and its related programmes in India. Are we in the rightdirection? J Clin Diagn Res 9(3):LE01-LE06.

5. Breuner CC, Mattson G; Committee on Adolescence; Committee on Psychosocial Aspects of Child and Family Health(2016). Sexuality Education for Children and Adolescents. Pediatrics 138(2). pii: e20161348.

6. Tragler A(1991). Health education in school children. Indian Pediatr 28(5):541-544.

7. Bhore PD, Bhore CP, Powar S, Nade AL, Kartikeyan S, Chaturvedi RM (1992).Child-to-parent education: a pilot study. Indian J Lepr 64(1):51- 57.

8. Sedighi I, Nouri S, Sadrosadat T, Nemati R, Shahbazi M (2012). Can children enhance their family's health knowledge? An Infectious Disease Prevention Program. Iran J Pediatr 22(4):493-498.

9. Rajan S, Roberts KJ, Guerra L, Pirsch M, Morrell E (2017). Integrating health education in core curriculum classrooms: successes, challenges, and implications for urban middle schools. $J$ Sch Health 87(12):949-957.

10. Martin A, Booth JN, Laird Y, Sproule J, Reilly JJ, Saunders DH (2018). Physical activity, diet and other behavioural interventions for improving cognition and school achievement in children and adolescents with obesity or overweight. Cochrane Database Syst Rev 3:CD009728. 